ГORIGINAL ARTICLE-

Volume 11 Issue 42019

DOI: 10.21315/eimj2019.11.4.5

\section{ARTICLE INFO}

Submitted: 17-11-2019

Accepted: 28-11-2019

Online: 31-12-2019

\title{
The Impact of Virtual Microscopy on Medical Students' Intrinsic Motivation
}

\author{
Anna Alicia Simok', Siti Nurma Hanim Hadie@Haji', Husnaida Abdul \\ Manan@Sulong ${ }^{2}$, Muhamad Saiful Bahri Yusoff ${ }^{3}$, Nor Farid Mohd \\ Noor', Mohd Asnizam Asari', Fazlina Kasim' \\ ${ }^{1}$ Anatomy Department, School of Medical Sciences, Universiti Sains \\ Malaysia, Kelantan, MALAYSIA \\ ${ }^{2}$ Integrative Medicine Cluster, Advanced Medical \& Dental Institute, \\ Universiti Sains Malaysia, Pulau Pinang, MALAYSIA \\ ${ }^{3}$ Medical Education Department, School of Medical Sciences, \\ Universiti Sains Malaysia, Kelantan, MALAYSIA \\ ${ }^{4}$ School of Dental Sciences, Universiti Sains Malaysia, Kelantan, \\ MALAYSIA
}

To cite this article: Simok AA, Hadie@Haji SNH, Abdul Manan@Sulong H, Yusoff MSB, Mohd Noor NF, Asari MA, Kasim F. The impact of virtual microscopy on medical students' intrinsic motivation. Education in Medicine Journal. 2019;11(4):47-59. tps://doi.org/10.21315/eimj2019.11.4.5

To link to this article: https://doi.org/10.21315/eimj2019.11.4.5

\section{ABSTRACT}

Virtual microscopy has been introduced into histology curricula as an approach to improve students learning. An important factor to ascertain students learning and achievement is by instigating and reinforcing students' intrinsic motivation hence, this study aims to compare the students' intrinsic motivation towards using virtual microscopy with optical microscopy in learning histology among medical students in Universiti Sains Malaysia. A randomised controlled study was conducted among 120 students from 2017/2018 academic session. The participants were divided into two groups, the virtual and optical microscopy groups, using stratified random allocation. During the one-day intervention, all participants attended a lecture on "Histology of the Eye", a slide demonstration and a practical session at respective labs according to their groups. Students' perceptions of their motivation on learning histology using their respective learning tool were evaluated by administering the Intrinsic Motivation Inventory, which measured students' perceived competence, interest, pressure and value score. The perceived competence score of virtual microscopy group was significantly higher compared to the optical microscopy group $(p=0.037)$. There was no significant difference between the two study groups in terms of interest, pressure and value score. The use of virtual microscopy as a learning tool gave students greater perceived competence in learning histology. However, it is premature to conclude from this finding, as intrinsic motivation is multifactorial. Future studies should predict the correlation between elements of virtual microscopy with the attributes of intrinsic motivation to provide a better view on the impact of virtual microscopy on students' motivation to learn histology.

Keywords: Intrinsic motivation, Virtual microscopy, Histology teaching and learning 


\section{INTRODUCTION}

Histology is the study of normal tissue morphology and it is a fundamental basic science component in the medical curriculum. Through histology, medical students would be able to understand the intricacies of a cell structure that collectively form different tissues and organs of the body, and correlate structure with function (1). A strong background in histology is essential for students to have a better understanding of macroscopic anatomy, physiology, biochemistry, as well as pathology (1-3). In addition, a solid foundation in histology is also essential for medical students to consolidate their understanding of a disease and thus, enhance their ability to diagnose difficult clinical cases (4).

Histology relies heavily on technology to allow visualisation of biological tissue microstructure. In 1590, the first prototype microscope, the two-lens microscope was constructed (5-6). It was later superseded by simple hand-held singlelens microscopes which included a small but powerful lens that provides higher magnification and better image quality. A major technical improvement of the microscope occurred in 1857, as Carl Zeiss, Ernst Abbe and Otto Schott enhanced the resolution of microscopes by developing high-performance stand-type compound microscopes (5-6). Ever since its inception, optical microscopy has been the cornerstone for histology analysis and learning. In parallel with the advancement of histology knowledge, optical microscopy has also evolved significantly, as more hybrid type of microscopy were being invented (e.g., confocal, electron, fluorescence, digital, atomic force and scanning tunnelling microscopes) (5-7). These modern types of microscopes increase the efficacy of optical microscope by improving its resolution in length and time (7).

Optical microscopy has been the fundamental laboratory tool used for teaching histology nevertheless, its use was echoed by novice users - including medical students - as difficult, frustrating and tiresome as they need to master their skills in getting the best magnification of the image (8-9). A user needs to know the process of acquiring a clear image by manipulating the stage and condenser, as well as obtaining the best magnification view, which definitely requires deliberate practice and assistance from a knowledgeable academic staff. As a result, students are not deeply engaged with learning using optical microscopy during practical sessions (10-11). Another limitation of optical microscopy is the inability to teach histological structures precisely to the students as they are not viewing the histology slide concurrently with the tutor (12). Although a multiviewer microscope would probably solve the problem, it could never cater a large number of students at one time. Hence, histology teaching would become time consuming and less effective (12-13). There is also a logistic issue with the use of optical microscopy, whereby maintaining the microscopes and replacing damaged histology slides are very costly (14). Such difficult learning environment would definitely influence students' motivation to learn histology. Hence, there was a pressing need among anatomy educators to reform the histology teaching in medical schools (14).

Concurrently, medical schools worldwide had undergone significant curricular reform that involved the integration of biomedical sciences with clinical sciences (15). As a result, the contact hours for basic sciences subjects including histology in medical schools were reduced (16). Consequently, anatomists and histologists began to innovate their teaching method as to cope with the changes. The most common alternative tool used for medical histology teaching is the virtual microscopy (13, 17-18). Virtual microscopy includes a slide scanner that converts selected glass slides into high-resolution digital images (i.e., virtual histology slides), computer servers to electronically store the virtual 
histology slides and software viewers that enables users to examine and analyse these digitised slides (19). Hence, with the help of the software viewers, virtual histology slides could be easily manipulated and shared during learning as to cater the learning needs of the students (17). Several studies exposing students to both virtual and optical microscopes, reported that majority of students preferred the virtual microscopes as compared to the optical microscopes $(9,11$, 14). The reasons provided by the students for their preference of virtual microscopes were; easier navigation of virtual histology slides with less strain on eyes, better posture during viewing of the virtual histology slides and clearer images $(9,11,14)$. In addition, a majority of the students also claimed that virtual microscopy enabled greater collaboration amongst students thus, facilitating students to become engaged and maintain their interest with the course material. Most students also claimed that virtual microscopy had positively enhanced their learning of the material $(9,11)$.

Likewise, histology teaching and learning in Universiti Sains Malaysia (USM) is conducted using both virtual and optical microscopy. During the practical session, a demonstration is done using the virtual microscope by an anatomy lecturer. After the demonstration, students get hands-on session in which groups of students share and take turns using the conventional optical microscopes and glass slides. The optical microscopes need frequent maintenance and are costly to repair if any damage occurs. Furthermore, the glass slides also fade throughout time and once a slide is broken, a new one needs to be purchased.

The aforementioned factors make the virtual microscopy financially more favourable in the long run. While many studies have reported successful transition to the virtual microscopy $(12,14,20)$, there is continuous debate on whether virtual microscopy is more effective as compared to the optical microscopy. Several studies revealed no significant difference of students' test performance between virtual and optical microscopy groups $(11,18,21)$. In contrary, other research have found that the virtual microscopy had significantly improved the academic performance of students (22-23). Apart from these inconsistent findings, there were very limited studies that explored the impact of both optical microscopy and virtual microscopy on other learning domains such as intrinsic motivation.

Ryan and Deci (24) defined intrinsic motivation as completing a task for its innate satisfaction rather than for some separable consequence. An individual is prompted to take action for the fun or challenge entailed rather than because of external pressures or reward when intrinsically motivated. When deciding a teaching and learning tool, intrinsic motivation is an important aspect to be considered because it instigates deeper processing, greater mastery and best implementation of learning (25-26). Intrinsically motivated students are more likely to persevere with challenging tasks. They also perform better academically as compared to students extrinsically motivated with incentives $(24,27)$. Hence this study aimed to compare the students' intrinsic motivation towards using virtual microscopy with optical microscopy in learning histology among medical students in USM.

\section{MATERIAL AND METHODS}

\section{Study Design, Study Population, Sampling Method, Study Subjects and Ethical Approval}

We conducted a randomised controlled study on the comparison of the effects of optical microscopy and virtual microscopy on medical students' intrinsic motivation towards learning histology. Our recruited subjects were Phase 1 medical students consisting of the first- and secondyear students, aged between 18 and 25 years, who had enrolled in the Doctor of Medicine Programme at School of 
Medical Sciences, USM Health Campus in Kubang Kerian, Kelantan, Malaysia for $2017 / 2018$ academic session. The study did not include students who are repeating Phase 1 of the programme. The sample size was 64 subjects per group based on Cohen Statistical Power Analysis (Behavioral Sciences) (28), taking into consideration the following; significance level $(\alpha)$ set at 0.05 , medium effect size and power of study is $80 \%$. We used purposive sampling method due to small population cohort (29). Out of 240 students who were eligible for this study, only 157 students agreed to participate and gave their written informed consents. The USM Human Ethic Research Committee had approved this study protocol.

\section{Research Group}

We performed group allocation using stratified random method to control confounding factors that may affect the study, which are gender and year of study. We divided the 157 consented students into four name lists which were the firstyear male students $(\mathrm{n}=24)$, first-year female students $(\mathrm{n}=65)$, second-year male students $(\mathrm{n}=26)$ and second-year female students $(n=42)$. From each list, we randomly selected the students using a random number generator to represent the optical microscopy group and the remaining unselected participants to represent the virtual microscopy group with a one to one ratio. Although initially the 157 students consented their participation, only 120 students attended the study. From these, 57 students were in the virtual microscopy group and 63 students in the optical microscopy group. All participants had experienced using optical microscopes in previous histology practical sessions in the programme curriculum.

\section{Research Tool}

We used histology glass slides of the eyeball and iris that were obtained from GinkgoMed Company, Taiwan for the optical microscopy histology practical sessions and photographed selected best slides of each at high magnification (40x) using a slide scanner (Zeiss Mirax Desk, Germany). We then uploaded the captured images into computer desktops where we viewed the images via the Pannoramic viewer software.

In this study, we adapted the validated Intrinsic Motivation Inventory (IMI) (24). The IMI is a multidimensional measurement tool designed to assess participants' subjective experience regarding the activity or intervention during an experiment. Several other studies related to intrinsic motivation and self-regulation has used similar tool (30-32). The survey consisted of four subscales; interest, perceived competence, pressure and value with 25 items. Students were requested to answer each item based on a five Likert scale; $1=$ strongly disagree; $2=$ disagree; 3 = unsure; 4 = agree; and $5=$ strongly agree. The interest subscale assesses the students' interest or enjoyment concerning learning histology by using the learning tool. This subscale is a self-report measurement of the intrinsic motivation. Learning tool here refers to either virtual or optical microscope according to their respective groups. The perceived competence subscale assesses the students' perception on how well they performed the task given using the learning tool. The task here refers to identifying histological structures seen from their glass slides or virtual slides. For the pressure subscale, it measures how burdensome or anxious the students felt while trying to identify histological features using either the virtual or optical microscopes. Lastly, the value subscale is to assess how much the students appreciate and values learning histology using either the virtual or the optical microscopes.

\section{The Intervention of the Study}

We conducted a one-day intervention on a weekend and 120 students attended this activity. The first activity was a one-hour 
lecture on histology of the eye delivered by an experienced lecturer in histology. The same lecturer conducted a slide demonstration session in the following 30 minutes. Afterwards, we briefed all the students regarding the practical session and provided them a printed histology workbook as a guide for them to identify histological structures and their features in the slides provided during the practical session. We then ushered the students to their designated laboratories according to the allocated intervention groups; the optical microscopy group and the virtual microscopy group for their respective practical session. Prior to this, the students were blind to which group they would be assigned.

During the one-hour practical session, we gave the students from the virtual microscopy group individual computers and three different virtual slides of the eye for them to view using the Pannoramic viewer software. Prior to the session, we gave the students basic instructions on how to operate the virtual microscope. For students of optical microscopy group, we gave them optical microscopes. However, there were not enough slides to accommodate a one-to-one ratio of student and glass slide. Therefore, two students shared a set of slides and each set had three different histology slides similar to the virtual slides used by the virtual microscopy group. Throughout the practical session, a lecturer experienced in teaching histology accompanied each group in their respective labs. After the practical session, students reassembled at the initial laboratories and answered the IMI questionnaire.

\section{Data Analysis}

We performed data analysis using Statistical Package for the Social Sciences (SPSS) software, version 22 (IBM Corp., Armonk, $\mathrm{NY}$ ). We entered the data, checked for data entry error, and missing values, explored and cleaned the data. Prior to running the statistical test, we checked assumptions and set significance level $(\alpha)$ at
0.05 with confidence interval of $95 \%$. We applied Mann-Whitney test to evaluate the differences of IMI subscales between the study groups. We used a non-parametric test because of assumptions of the independent $t$-test were not met. The outcome variable was not-normally-distributed in each group. We calculated the Cohen effect size using effect size calculator for $t$-test (33-34).

\section{RESULTS}

All 120 students, which comprised of 57 students in the virtual microscopy group and 63 students in the optical microscopy group, had completed the IMI questionnaire. We evaluated the intrinsic motivation score based on each subscale, interest, perceived competence, pressure, and value, and compared between the study groups. This is to determine whether the learning tool used influenced students' self-motivation to learn.

Table 1 shows that only the subscale of perceived competence showed a significant difference between the study groups. The median (IQR) of perceived competence score for the virtual microscopy group [23(4.50)] was significantly higher compared to optical microscopy group [22(6.00)], $p=0.037$. This indicates that the students from virtual microscopy group felt they learned histology very well using the virtual microscope in the practical session. For other subscales, there were no significant difference between the study groups. Hence, students from both virtual and optical microscopy groups were similar in terms of interest and pressure while using the learning tool. Furthermore, both study groups felt their respective learning tool were useful in learning histology.

\section{DISCUSSION}

This study has identified positive impact of virtual microscopy on students' perceived competence, an attribute of intrinsic motivation. On the other hand, the impact of virtual microscopy on other attributes of 
Table 1: Comparison of intrinsic motivation scores between study groups

\begin{tabular}{|c|c|c|c|c|c|}
\hline \multirow[b]{2}{*}{ Variables } & \multicolumn{2}{|c|}{ Median (IQR) } & \multirow[b]{2}{*}{ z-statistics } & \multirow[b]{2}{*}{$p$-value } & \multirow[b]{2}{*}{$\begin{array}{l}\text { Cohen effect } \\
\text { size (d) }\end{array}$} \\
\hline & $\begin{array}{c}\text { Virtual } \\
\text { microscopy } \\
\text { group }(n=57)\end{array}$ & $\begin{array}{c}\text { Optical } \\
\text { microscopy } \\
\text { group }(n=63)\end{array}$ & & & \\
\hline Interest score & $29(5.50)$ & $27(5.00)$ & -1.527 & 0.127 & 0.344 \\
\hline $\begin{array}{l}\text { Perceived competence } \\
\text { score }\end{array}$ & $23(4.50)$ & $22(6.00)$ & -2.085 & 0.037 & 0.474 \\
\hline Pressure score & $10(4.00)$ & $11(7.00)$ & -0.657 & 0.511 & 0.224 \\
\hline Value score & $33(4.00)$ & $32(7.00)$ & -1.505 & 0.132 & 0.341 \\
\hline
\end{tabular}

Note: Mann-Whitney test was applied to determine the difference between study groups. Significance level was set at 0.05. IQR = Interquartile range. Cohen effect size was calculated using effect size calculator for $t$-test, (33-34). Cohen effect size threshold: small $=0.20$, medium $=0.50$, large $=0.80$, very large $=1.13(28)$.

intrinsic motivation (i.e., interest, values and pressure) was not found to be superior to optical microscopy. Taken together, these results suggest that the use of virtual microscopy in this study failed to fully stimulate students' intrinsic motivation when compared to optical microscopy.

Out of the four measured subscales, perceived competence was the only one that showed a significant difference between the two study groups. The result was in keeping with previous studies that documented students' perception on the use of the virtual microscopy, which was described to be convenient and user-friendly $(20,35)$. In contrast, a previous study by Helle et al. (36) revealed no significant difference in perceived competence between the virtual microscopy and optical microscopy groups. It was reported in the author's study that students in virtual microscopy group faced difficulty while viewing and creating annotations. Since the annotation feature was not used in our study, we believed that the use of virtual microscopy was troublefree as the students did not need to apply additional skills while using the virtual microscopy.

Out of the four evaluated subscales, only perceived competence score of the virtual microscopy group was shown to be significantly higher than the optical microscopy group. In our study, perceived competence refers to the student's ability to obtain a focused image of the eyeball tissue; and navigating the tissue for identification of important histological structures, using the assigned microscope. The higher perceived competence of the virtual microscopy indicates that the students were at ease while getting a focused image using the trouble-free tool. The result was in keeping with previous studies that documented students' perception on the use of the virtual microscopy, which was described to be convenient and user-friendly $(20,35)$. Nevertheless, the use of optical microscopy has a drawback. The task of using optical microscopy requires the students to be familiar with the compartments of microscopes, their functions and steps in obtaining a clear and focused image (10). Hence, these technical difficulties might have led to an incompetent impression of themselves. Interestingly, the students have had deliberate practice of the optical microscope during previous practical sessions. Despite this advantage, students of the optical microscopy still felt they were incompetent in handling/using the optical microscopy. This postulation further strengthened the fact that virtual microscopy is user-friendly $(20,35)$

Glass slide variability is also one factor that could have given the optical microscopy participants the perception of being incompetent in learning (37). With a good 
quality tissue section, he or she would be able to identify the histological features of the tissue well enough and perceive himself or herself to be competent. Adversely, with a tissue section of less quality, he or she might face difficulty in identifying the histological features, and thus resulting in the perception of being incompetent. In our study, the quality of the slides was carefully screened and selected. However, the discrepancy between the glass slides cannot be eliminated. Unlike the glass slides, the virtual slides were duplications of the single best quality section. Hence, all participants of the virtual microscopy group received identical virtual slides of the best quality.

On the other aspect, our study showed that both virtual and optical microscopy were not supreme over the other regarding stimulation of interest. Interestingly, the calculated Cohen effect size was 0.344 with a slightly higher interest score of the virtual microscopy group. This finding suggests that the use of different types of microscopes had given an impact to students' interest despite it to be not significant. There are limited studies that evaluated the impact of virtual microscopy on students' interest attribute. One of which is a study conducted by Helle et al. (36) that has also shown an insignificant finding of interest score. The study postulated that a one-week period of exposure to the virtual microscopy was very short, which prevented the development of interest on learning histology. It was described that students could have only begun to familiarise themselves with the virtual microscopy; and therefore, require more time to adapt to the new tool to be able to perceive it as an enjoyable activity. This finding is in concordance with the present study in which participants applied the virtual microscopy for a much shorter period compared to study conducted by Helle et al. (36).

Our postulation is aligned with the fourphased model of interest development by Harackiewicz et al. (38), which described interest as an enduring predisposition to re-engage with a particular subject over- time. Although a particular situational trigger could promote a person's interest, the trigger should be stable and dynamic enough to ensure sustainability of the interest (39-40). To maintain a situational trigger in learning context, it is vital to incorporate structural features that could stimulate attention, enjoyment and context personalisation (38). In this study, context personalisation could have been achieved more by the optical microscopy group in view of the active students' participation during handling of the light microscope.

Although it could be argued that the use of technology-enhanced learning in virtual microscopy group could have an impact on students' interest as shown by its higher interest score, there is limited evidence to conclude the effectiveness of technology-enhanced learning on students' interest. A previous study by Granito and Chernobilsky (41) reported almost equal percentage of students' who prefer and did not prefer using technology during learning and completion of project task. Despite higher students' performance in technology-based group, Granito and Chernobilsky (41), reported that students' interest was influenced by many factors such as their interest, background, previous experience using technology and availability of technology. Since virtual microscopy was not available for students' use in our institution prior to this research, the students might had struggled to make themselves familiar with the new tool: and therefore, prevent the stimulation of their interest (42). Moreover, the interest subscale is considered as a selfreport measure of the intrinsic motivation inventory (43). Like other self-report measures, the interest subscale alone cannot be simply interpreted. Many factors must be considered such as ego-involvements, selfpresentation styles and other psychological dynamics.

Apart from that, this study failed to prove that virtual microscopy imposed less pressure to the students while learning histology. The score was slightly higher in 
the control group with effect size of more than 0.2 , indicating that optical microscopy might have imposed a little more pressure to the students despite the insignificant difference.

This assumption is supported by the result of a previous study, which demonstrated a significantly lower pressure score in virtual microscopy group compared to optical microscopy (36). The positive result of the virtual microscopy group was described to be contributed by the post-practical task given to the students, who were free to study at their own pace, place and time (36). While the optical microscopy group had to attend the regular demonstration led by their lecturer and with no privilege to conduct a post-practical assignment (36). The freedom to study at student's own place, pace and time with an easily accessible virtual microscope might have reduced their anxiety and stress level in learning histology. In contrary, participants in the present study were not exposed to the virtual microscope outside the allocated practical session. Hence, the difference of pressure score between virtual microscopy and optical microscopy was very trivial.

We postulated that the trivial difference of pressure score between the two group was contributed by the factor of deliberate practice. Deliberate practice and previous exposure have been identified as important factors that determine the acquisition and mastery of various skills (44-45). The students of the optical microscopy group had been exposed to optical microscopy repeatedly during histology practical sessions. During each session, the students deliberately use optical microscopy for learning the histological features of the biological tissue. In other words, the students were familiar with optical microscopy during the research lecture; and thus, felt minimal pressure of learning histology of the eye using the tool. Likewise, students in the virtual microscopy group were perhaps comfortable in using their learning tool despite it being new to them. The use of virtual microscope is similar with using a computer or laptop, which is a skill that they acquired. Moreover, the virtual slides were easy to open from files and easily navigated as they were already in focus (18). The students only need to drag the cursor to change fields and select the magnification buttons to obtain a good magnification of the image. The above conditions could have also contributed to the trivial difference of pressure score between the two groups.

Likewise, our study showed no significant difference of the perceived value score between the two groups. Interestingly, the value score was higher in virtual microcopy group with medium effect size, which might indicate the occurrence of actual difference in the perceived value of the two learning tools, despite the results to be statistically not significant. Hence, we argued that students of the virtual microscopy group might have perceived more value on using the tool compared to those in the optical microscopy group during the intervention. In fact, the educational values of virtual microscopy have been well-documented in several previous studies (46-48). For instance, the use of virtual microscopy in learning ophthalmic pathologic slides among ophthalmology residents of several leading institutions, was perceived to have positive educational value (46). Correspondingly, a study by Yin and colleagues (47) provided supporting evidences on enhanced educational value of virtual microscopy which was described as a whole slide digital imaging - beyond the capacity of fixed histology images and text. Similarly, a study by Saco et al. (48) described several affective learning values of virtual microscopy that were achieved through collaborative activities and interaction among students.

Nevertheless, the study by Helle and colleagues (36) revealed significantly higher value score of the optical microscopy compared to the virtual counterpart, and thus supports our insignificant result. Helle and colleagues (36) reported that integration of modern technology into the conventional teaching method could not occur overnight, and therefore participants 
could not assess and appreciate the full potential of virtual microscopy. It was reported that students' pre-determined idea and perception on the best tool for learning histology slides was accounted for higher students' appreciation in using the tool (49). In previous decade, students' have difficulty to accustomed with learning histological slides without optical microscope $(14,50)$, and thus resulted in higher perceived value in using optical microscopy for learning histology. This factor could perhaps explain the insignificant results of our study as our participants have continuous exposure to hands-on experience using optical microscopy during their regular practical histology sessions. In our study, the participants in the virtual microscopy group only applied the learning tool for a short one-hour session, thus resulted to the insignificant difference of value score.

However, it should be noted that the medium effect size of the value score result in this study indicates that students perceived some form of appreciation on using virtual microscope as a learning tool. These students have passively been exposed to virtual microscopy during regular demonstrations sessions by the anatomists. Hence, we postulate that the participants had enough exposure to assessed and appreciate the potential of learning histology using the virtual microscope, either individually or in large groups during demonstrations. As for the optical microscopy participants, they too valued their learning tool, in which they were accustomed to after a few semesters. Furthermore, a study revealed that even after successful transition to the virtual microscope, there were still $25 \%$ of the medical students who found it useful to use both the virtual and optical microscopes (12).

\section{LIMITATIONS}

This study has some limitations. One of which is regarding the small sample size due to high non-participation rate and short intervention duration. Some of the first-year and second-year students had other academic activities on the same day of the research, which were compulsory for them. Apart from that, the student's prior experience of using the optical microscope was another overlooked factor. Having previous experience on using optical microscopy would affect students' perceptions on the impact of their assigned learning tool to the various aforementioned attributes of intrinsic motivation.

\section{RECOMMENDATION FOR FUTURE RESEARCH}

Addressing the limitations in this present research, it is suggested for the future research to increase the sample size in the future study and the target population should be confined to first-year medical students, excluding repeating students. This condition will minimise the possibility of prior experience using the optical microscope. Furthermore, it would be beneficial to integrate the study into the official academic programme structure addressing the limitation of the short intervention period, minimise scheduling conflict and increase sample size by allowing all students to participate. The intervention period can be prolonged and more follow-up study can be done.

\section{CONCLUSION}

The interest subscale is considered the selfreport measure of intrinsic motivation (43). Thus, saying the intrinsic motivation of the virtual microscopy and optical microscopy groups were comparable is fair. However, other factors must be considered to properly interpret the interest score alone such as students' background and psychological dynamic. Furthermore, the perceived competence subscale is theorised to be the positive predictor of intrinsic motivation and the pressure subscale as the negative predictor (43). Hence, if the positive 
predictors in this study are significantly high and there is no significant negative predictor, it is expected that there should be a significant difference in the interest subscale which was not the case. It could be argued that intrinsic motivation is influenced by many factors. Therefore, the effects of virtual microscopy on students' intrinsic motivation cannot be concluded. In order to understand the impact of virtual microscopy and optical microscopy on student's internal motivation, future studies should aim to predict the correlation between elements of these microscopy with the attributes of intrinsic motivation. Such effort would provide a better view on the impact of virtual microscopy on students' motivation to learn histology. Nonetheless, this study proved that virtual microscopy had a positive impact on student's perceived competence in learning histology. Hence, the virtual microscopy can be used in histology teaching to optimise students perceived competency in learning histology.

\section{ETHICAL APPROVAL}

This study obtained ethical approval from Universiti Sains Malaysia Human Ethic Research Committee (JEPeM) (JEPeM USM Code: USM/JEPeM/15100338).

\section{ACKNOWLEDGEMENTS}

The authors would like to thank the Universiti Sains Malaysia for allowing us to conduct this study in their institution and for providing funding for this study (Universiti Sains Malaysia Short Term Grant [304/PPSP/61313040]). We would also like to thank the supporting staffs of the Department of Anatomy, School of Medical Sciences who provided all the technical support needed during the study. Last but not least, our greatest appreciation to the pre-clinical years medical students who participated in this study.

\section{REFERENCES}

1. Hortsch M. From microscopes to virtual reality - how our teaching of histology is changing. J Cytol Histol. 2013;4(3):e108. https://doi.org/10.4172/2157-7099.1000e108

2. Parker EU, Reder NP, Glasser D, Henriksen J, Kilgore MR, Rendi $\mathrm{MH}$. NDER: a novel web application for teaching histology to medical students. Acad Pathol. 2017;10(4):1-5. https://doi. org/10.1177/2374289517691061

3. Zaletel I, Marić G, Gazibara T, Rakočević J, Labudović Borović M, Puškaš N, et al. Relevance and attitudes towards histology and embryology course through the eyes of freshmen and senior medical students: experience from Serbia. Ann Anat. 2016;208:217-21. https://doi.org/10.1016/j. aanat.2016.07.002

4. Lisk K, Agur AM, Woods NN. Exploring cognitive integration of basic science and its effect on diagnostic reasoning in novices. Perspect Med Educ. 2016;5(3):147-53. https://doi.org/10.1007/s40037-016-0268-2

5. Araki T. The history of optical microscope. Mech Eng Rev. 2017;4(1):1-8. https://doi. org/10.1299/mer.16-00242

6. Hussein IH, Raad M, Safa R, Jurjus R, Jurjus A. Once upon a microscopic slide: the story of histology. J Cytol Histol. 2015; 6(6):1-4. https://doi.org/10.4172/2157-7099 .1000377

7. Wollman AJ, Nudd R, Hedlund EG, Leake MC. From animaculum to single molecules: 300 years of the light microscope. Open Biol. 2015;5(4):150019. https://doi. org/10.1098/rsob.150019

8. Wilson AB, Taylor MA, Klein BA, Sugrue MK, Whipple EC, Brokaw JJ. Meta-analysis and review of learner performance and preference: virtual versus optical microscopy. Med Educ. 2016;50(4):428-40. https://doi. org/10.1111/medu.12944 
9. McCready ZR, Jham BC. Dental students' perceptions of the use of digital microscopy as part of an oral pathology curriculum. J Dent Educ. 2013;77(12):1624-8.

10. Azubuike A, Azubuike AS. Students' common difficulties in manipulating microscope selected schools in Kano State, Nigeria. Creative Education. 2014;5(13):1125-31. https://doi. org/10.4236/ce.2014.513127

11. Farah CS, Maybury T. Implementing digital technology to enhance student learning of pathology. Eur J Dent Educ. 2009;13(3):172-8. https://doi.org/10.1111/ j.1600-0579.2009.00570.x

12. Blake CA, Lavoie HA, Millette CF. Teaching medical histology at the University of South Carolina School of Medicine: transition to virtual slides and virtual microscopes. Anat Rec B New Anat.2003;275(1):196-206. https://doi. org/10.1002/ar.b.10037

13. Husmann PR, O'Loughlin VD, Braun MW. Quantitative and qualitative changes in teaching histology by means of virtual microscopy in an introductory course in human anatomy. Anat Sci Educ. 2009;2(5):218-26. https://doi.org/10.1002/ ase. 105

14. Krippendorf BB, Lough J. Complete and rapid switch from light microscopy to virtual microscopy for teaching medical histology. Anat Rec B New Anat. 2005;285(1):19-25. https://doi.org/10.1002/ar.b.20066

15. Drake RL. A retrospective and prospective look at medical education in the United States: trends shaping anatomical sciences education. J Anat. 2014;224(3):256-60. https://doi.org/10.1111/joa.12054

16. Williams G, Lau A. Reform of undergraduate medical teaching in the United Kingdom: a triumph of evangelism over common sense. BMJ. 2004;329(7457):92-4. https://doi. org/10.1136/bmj.329.7457.92
17. Collier L, Dunham S, Braun MW, O'Loughlin VD. Optical versus virtual: teaching assistant perceptions of the use of virtual microscopy in an undergraduate human anatomy course. Anat Sci Educ. 2012;5(1):10-9. https://doi.org/10.1002/ ase. 262

18. Mione S, Valcke $M$, Cornelissen $M$. Evaluation of virtual microscopy in medical histology teaching. Anat Sci Educ. 2013;6(5):307-15. https://doi.org/10.1002/ ase. 1353

19. Jonas-Dwyer D, Sudweeks F. Informing students using virtual microscopes and their impact on students' approach to learning. Informing Sci J. 2007;10:61-70. https://doi. org $/ 10.28945 / 456$

20. Ordi O, Bombí JA, Martínez A, Ramírez J, Alòs L, Saco A, et al. Virtual microscopy in the undergraduate teaching of pathology. J Pathol Inform. 2015;6:1. https://doi. org/10.4103/2153-3539.150246

21. Scoville SA, Buskirk TD. Traditional and virtual microscopy compared experimentally in a classroom setting. Clin Anat. 2007;20:565-70. https://doi.org/10.1002/ ca. 20440

22. Tian Y, Xiao W, Li C, Liu Y, Qin M, Wu Y, et al. Virtual microscopy system at Chinese medical university: an assisted teaching platform for promoting active learning and problem-solving skills. BMC Med Educ. 2014;14(1):74. https://doi. org/10.1186/1472-6920-14-74

23. Solberg BL. Digital and traditional slides for teaching cellular morphology: a comparative analysis of learning outcomes. Clin Lab Sci. 2012;25(4):12-8.

24. Ryan RM, Deci EL. Self-determination theory and the facilitation of intrinsic motivation, social development, and wellbeing. Am Psychol. 2000;55(1):68-78. https://doi.org/10.1037//0003-066x.55.1.68 
25. Kusurkar RA, Ten Cate TJ, Van Asperen $\mathrm{M}$, Croiset G. Motivation as an independent and a dependent variable in medical education: a review of the literature. Med Teach. 2011;33(5):e242-62. https://doi.org/ 10.3109/0142159X.2011.558539

26. Covington MV. Goal theory, motivation and school achievement: an integrative review. Annu Rev Psychol. 2000;51:171200. https://doi.org/10.1146/annurev. psych.51.1.171

27. Walker CO, Greene BA, Mansell RA. Identification with academics, intrinsic/ extrinsic motivation, and self-efficacy as predictors of cognitive engagement. Learning and Individual Differences. 2006;16(1):1-12. https://doi.org/10.1016/j. lindif.2005.06.004

28. Cohen J. Statistical power analysis for the behavioural sciences. 2nd ed. New York: Lawrence Erlbaum Associates; 1988.

29. Crossman A. Understanding purposive sampling: an overview of the method and its applications. 2018 [cited 12 October 2017]. Available from: https:/www.thoughtco.com/ purposive-sampling-3026727

30. Ryan RM. Control and information in the intrapersonal sphere: an extension of cognitive evaluation theory. Journal of Personality and Social Psychology. 1982;43(3):450-61. https://doi. org/10.1037/0022-3514.43.3.450

31. Ryan RM, Koestner R, Deci EL. Varied forms of persistence: when free-choice behavior is not intrinsically motivated. Motivation and Emotion. 1991;15:185-205. https://doi.org/10.1007/BF00995170

32. Deci EL, Eghrari H, Patrick BC, Leone DR. Facilitating internalization: the self-determination theory perspective. J Pers. 1994;62(1):119-42. https://doi. org/10.1111/j.1467-6494.1994.tb00797.x
33. Faul F, Erdfelder E, Lang AG, Buchner A. $G^{\star}$ Power 3: a flexible statistical power analysis program for the social, behavioral, and biomedical sciences. Behavior Research Methods. 2007;39:175-91. https://doi. org/10.3758/BF03193146

34. Social Science Statistic. Effect size calculator for t-test 2015. [cited 1 March 2018]. Available from: http://www.socscistatistics. com/effectsize/Default3.aspx

35. Hande AH, Lohe VK, Chaudhary MS, Gawande MN, Patil SK, Zade PR. Impact of virtual microscopy with conventional microscopy on student learning in dental histology. Dent Res J (Isfahan). 2017;14(2):111-16.

36. Helle L, Nivala M, Kronqvist P, Gegenfurtner A, Björk P, Säljö R. Traditional microscopy instruction versus process-oriented virtual microscopy instruction: a naturalistic experiment with control group. Diagn Pathol. 2011;6(Suppl 1):S8. https://doi.org/10.1186/1746-1596-6S1-S8

37. Bloodgood RA, Ogilvie RW. Trends in histology laboratory teaching in United States medical schools. Anat Rec B New Anat. 2006;289(5):169-75. https://doi. org/10.1002/ar.b.20111

38. Harackiewicz JM, Smith JL, Priniski SJ. Interest matters: the importance of promoting interest in education. Policy Insights Behav Brain Sci. 2016;3(2):220-7. https://doi.org/10.1177/2372732216655542

39. Renninger KA, Hidi SE. The power of interest for motivation and engagement. New York: Routledge; 2016. https://doi. org/10.4324/9781315771045

40. Hidi S, Renninger KA. The four-phase model of interest development. Educational Psychologist. 2006;41(2):111-27. https:// doi.org/10.1207/s15326985ep4102_4 
41. Granito M, Chernobilsky E. The effect of technology on a student's motivation and knowledge retention. NERA conference proceedings. 2012. p. 17.

42. Carrabba C, Farmer A. The impact of project-based learning and direct instruction on the motivation and engagement of middle school students. LATER. 2018;1(2):163-74.

43. Monteiro V, Mata L, Peixoto F. Intrinsic motivation inventory: psychometric properties in the context of first language and mathematics learning. Psicol Reflex Crit. 2015;28(3):434-43. https://doi.org/ 10.1590/1678-7153.201528302

44. Ericsson K. The influence of experience and deliberate practice on the development of superior expert performance. In: Ericsson $\mathrm{K}$, Charness N, Feltovich P, Hoffman $\mathrm{R}$, editors. The Cambridge handbook of expertise and expert performance (Cambridge handbooks in psychology). Cambridge: Cambridge University Press. 2006. p. 683-704. https://doi.org/10.1017/ CBO9780511816796.038

45. Ericsson KA. Deliberate practice and the acquisition and maintenance of expert performance in medicine and related domains. Acad Med. 2004;79(10 Suppl):S70-81. https://doi.org/10.1097/ 00001888-200410001-00022
46. Nikolic N, Espiritu B, Edward DP, Perlman J. Optimizing resident education of ophthalmic pathology: qualitative assessment of annotated virtual microscopy web site. J Clin Acad Ophthalmol. 2016;8(1):e39-41. https://doi.org/10.1055/s-0036-1581110

47. Yin F, Han G, Bui MM, Gibbs J, Martin I, Sundharkrishnan L, et al. Educational value of digital whole slides accompanying published online pathology journal articles: a multi-institutional study. Arch Pathol Lab Med. 2016;140(7):694-7. https://doi. org/10.5858/arpa.2015-0366-OA

48. Saco A, Bombi JA, Garcia A, Ramírez J, Ordi J. Current status of whole-slide imaging in education. Pathobiology. 2016;83(2-3):79-88. https://doi.org/10.1159 /000442391

49. Becerra D, Grob M, Rodriguez A, Barker MJ, Consiglieri L, Ferri G, Sabag N. Academic achievement and perception of two teaching methods in histology: light microscopy and digital systems. Int $\mathrm{J}$ Morphol. 2015;33(3):811-6. https://doi. org/10.1159/000442391

50. Lei LW, Winn W, Scott C, Farr A. Evaluation of computer-assisted instruction in histology: effect of interaction on learning outcome. Anar Rec. 2005;284(1):28-34. https://doi.org/10.1002/ar.b.20062 